\title{
Nanoscale morphology, structure and fractal study of kefir microbial films grown in natura
}

\author{
Robert S. Matos ${ }^{1,2 *}$ (D), Ellen C. M. Gonçalves ${ }^{1}$ (D), Erveton P. Pinto ${ }^{1}$ (D), Gerson A. C. Lopes ${ }^{1,3}$ (i), \\ Nilson S. Ferreira ${ }^{4}$ (D) and Cristiane X. Resende ${ }^{1}$ (B) \\ 'Laboratório de Biomateriais, Programa de Pós-graduação em Ciência e Engenharia de Materiais, \\ Universidade Federal de Sergipe - UFS, São Cristóvão, SE, Brasil \\ ${ }^{2}$ Grupo de Materiais Amazônicos, Departamento de Física, Universidade Federal do Amapá - UNIFAP, \\ Macapá, AP, Brasil \\ ${ }^{3}$ Laboratório de Física, Universidade do Estado do Amapá - UEAP, Macapá, AP, Brasil \\ ${ }^{4}$ Departamento de Física, Universidade Federal de Sergipe - UFS, São Cristóvão, SE, Brasil \\ *amazonianmaterialsgroup@gmail.com
}

\begin{abstract}
Kefir is a natural probiotic produced by kefir grains fermentation. Biofilms produced from fresh kefir grains in natura were studied for presenting structural characteristics that will be of great interest in the area of regenerative medicine. This work presents a study on the surface of kefir biofilms, obtained by the cultivation of kefir grains in commercial white sugar. Four different films were produced, varying the concentration of sugar. The crystallinity of the biofilms was analyzed and revealed that sugar concentration influences biofilm amorphousness. Morphology showed that the biofilms presented excellent superficial adhesiveness. Fractal parameters were studied and revealed that there was homogeneity in the biofilm microtexture. Both fractal succolarity and surface entropy showed that the degree of water penetration and topographic homogeneity of the biofilms was not influenced by sugar concentration. These results show that kefir biofilms have excellent structural and morphological properties to be used in the biomedical field.
\end{abstract}

Keywords: kefir, biofilms, crystallinity, morphology, fractal.

How to cite: Matos, R. S., Gonçalves, E. C. M., Pinto, E. P., Lopes, G. A. C., Ferreira, N. S., \& Resende, C. X. (2020). Nanoscale morphology, structure and fractal study of kefir microbial films grown in natura. Polímeros: Ciência e Tecnologia, 30(3), e2020033. https://doi.org/10.1590/0104-1428.04020

\section{Introduction}

The use of natural products in the treatment of several diseases has been studied since ancient times. Historically, human disease problems were treated using drugs extracted from classical medicinal plants. Skin disorders were treated with the use of natural plant extracts by traditional peoples a long time ago. However, at the beginning of the last century, there was an increase in the development of synthetic drugs that could definitively treat or cure these problems, but which later came up against the problem of the toxicity of these drugs. Currently, regenerative medicine has again turned to the use of natural products that may be more biocompatible and less cytotoxic to humans ${ }^{[1]}$. Biopolymers have had high relevance in this aspect because they are biodegradable ${ }^{[2]}$ and accurately extracted from natural products.

Kefir is a natural product well-known in traditional medicine as a probiotic drink produced from kefir grains ${ }^{[3]}$. The kefir grains are small rigid yellowish granules with irregular shapes ${ }^{[4]}$ containing bacteria and yeasts. Moreover, kefir grains also have in their composition proteins and polysaccharides ${ }^{[5]}$. Kefir grains are composed of a mixture of several bacteria, including various species of lactobacilli, lactococci, leuconostocs and acetobacteria, and yeasts (with

or without lactose fermentation $)^{[6]}$. This ensures that its composition is extremely diversified and rich, presenting great potential for regenerative medicine applications; however, the organization of the microorganisms in the grain is not entirely known ${ }^{[7]}$.

The grains are capable of producing an exopolysaccharide matrix, known as kefiran, which is much studied today. This polysaccharide has been presented as an excellent alternative for application in some fields such as tissue engineering ${ }^{[8]}$, regenerative medicine ${ }^{[9]}$, and drug delivery ${ }^{[10,11]}$. However, this polysaccharide matrix has also been observed to harbor microorganisms such as bacteria and yeasts ${ }^{[3]}$.

Microbial films can be found in the natural aquatic environment, soil, living tissues, medical devices, or piping systems for potable or industrial water. As a result of the symbiotic cooperation between bacteria, they form a layer on the surface that remains in constant maintenance ${ }^{[12]}$ until the environment is no longer favorable $e^{[13]}$. Thus, bacteria can quickly form complex living communities, preferably in aggregates ${ }^{[14]}$. Therefore, the biofilms can be understood as a community of microorganisms that tend to adhere to 
wet surfaces, to multiply themselves, and to get soaked in a viscous matrix composed of extracellular polymeric substances $(\mathrm{EPS})^{[15,16]}$. Thus, it is believed that a similar polysaccharide matrix can be produced by kefir grains in natura, by the formation of a biofilm on the substrate ${ }^{[17,18]}$, which can be a natural juice, a sugar solution, cane molasses or animal milk.

Nowadays, the most used substrate for growing water kefir grains is brown sugar because it is a product that undergoes little processing. However, from an economic point of view, this type of sugar is the most unviable and has high-cost compared to commercial white sugar. Furthermore, it worth highlighting that white sugar has fewer nutrients and more sucrose as compared to brown sugar ${ }^{[19,20]}$. Thus, it is interesting to study the consequences of using commercial white sugar for the production of biofilms for a potential application in regenerative medicine. Some researches have reported that kefiran films can have distinct applications on the food ${ }^{[21]}$ and pharmaceutical industries ${ }^{[3]}$. The reason for the application kefir biofilms on the biomedical field (e.g., biocurative) is that it presents a uniform distribution of bacteria that can act to protect the wound against pathogens microorganisms, moreover, according to Coma et al. ${ }^{[2]}$ biodegradable films can be functional, acting as antimicrobial or antioxidant agents.

Atomic force microscopy (AFM) has been successfully used to study this kind of biological surface as a result of its high sensitivity, e.g., see ${ }^{[3,22]}$. Several quantitative parameters are used to describe the information contained on the surface. As an example, we can mention the determination of the number of cells present in the biological tissue, the calculation of the shapes of the contours of a cell, or even the determination of the distribution of a specific population of a group of cells ${ }^{[23]}$. However, more quantitative parameters, such as roughness, asymmetry, and kurtosis, can provide accurate information about the topographic condition of the surface. In this present work, we are introducing three new parameters, such as surface entropy, fractal succolarity, and fractal lacunarity, to study biofilms surface texture. These parameters were successfully presented by Ştefan et al. ${ }^{[2]}$ for the description of the homogeneity behavior of the superficial microtexture.

A recent study has suggested that the surface of kefir biofilms has excellent superficial adhesiveness and is semi-crystalline, even when produced with brown sugar ${ }^{[3]}$. In this research, we propose the synthesis of these biofilms using white sugar as a substrate because of its lower cost. Thus, this work aims to evaluate the behavior of the structure, morphology, and microtexture on the surface of kefir biofilms. The analyzes were made using different methodologies such as X-ray diffraction (XRD), scanning electron microscopy (SEM), and atomic force microscopy (AFM). These results are significant in evaluating the possible applications of these exopolysaccharide-based biofilms.

\section{Materials and Methods}

\subsection{Materials}

The kefir grains were obtained at the Drugs Research Laboratory of the Federal University of Amapá, Brazil, and kept refrigerated for conservation. The white and brown sugars used in this research were purchased at a local supermarket in the Macapá/AP, Brazil. The grains were submitted to a process of stabilization of the microorganisms during 15 days, for maintenance of the grains viability. In this regard, a stirred white sugar solution (15 g.L $\left.\mathrm{L}^{-1}\right)$ was prepared. Then, the grains were added in this solution in a ratio 1:10 (w/v). The stirred solution was changed daily and the temperature kept at $27 \pm 2{ }^{\circ} \mathrm{C}$.

\subsection{Biofilms obtention}

The biofilm cultivation methodology previously proposed by Oliveira et al. ${ }^{[17]}$ was used. The biofilms were produced in a solution containing distilled water, kefir grains, and commercial white sugar. Four different experiments were performed, where $40 \mathrm{~g} . \mathrm{L}^{-1}$ of Kefir were inoculated in the following concentrations of white sugar: 20 g.L $\mathrm{L}^{-1}, 40$ g.L $\mathrm{L}^{-1}$, 60 g.L. ${ }^{-1}$, and 80 g.L $\mathrm{L}^{-1}$, respectively. A film grown only in the presence of brown sugar solution $\left(40\right.$ g. $\left.\mathrm{L}^{-1}\right)$ was obtained to be used as a basis for comparisons to the analysis of the surface topography and crystallography of the biofilms, following the same methodology proposed by Matos et al. ${ }^{[3]}$. This film was named control. Afterward, all the produced samples were kept at $25 \pm 2{ }^{\circ} \mathrm{C}$ for 25 days during its formation and posteriorly deposited on glass slides (Rectangular Microscope Slide Coverglass).

\subsection{Characterization of the biofilms}

\subsubsection{X-Ray Diffraction (XRD)}

The biofilms were cut out while still on the glass slide in dimensions that varied between 2 and $4 \mathrm{~cm}^{2}$ and kept in a sample holder made of glass and with side coating of aluminum. The measurements were performed at room temperature on a Miniflex II Rigaku diffractometer using $\mathrm{Cu} \mathrm{K}-\alpha(=1.542 \AA)$ tube operated at $40 \mathrm{kV}$ and $1.2 \mathrm{~mA}$, a scan range from 5 to $45^{\circ}(2 \theta)$, a step size of $0.02^{\circ}$, and scan-speed of $1 \% \mathrm{~min}$. The contributions of the amorphous and crystalline phases to the diffraction pattern was characterized by the empirical structure factors calculated via Le Bail method ${ }^{[25]}$ because of the large overlapped peaks on XRD patterns. The analysis was performed using the Fullprof program ${ }^{[26]}$, with the space group and unit cell parameters found in the indexing. Peak profiles were modeled using a pseudo-Voigt peak shape function in order to fit the various parameters to the data point such as one scale factor, one zero shift, background, three cell parameters, width of the peaks, and one overall thermal factor.

The crystallinity percentage of the biofilms was estimated, separating the integrated intensities from the crystalline and noncrystalline phases of the Le Bail fitted XRD patterns using Equation 127]:

$$
C_{e s t}=100 I_{c} /\left(I_{a}+I_{c}\right)
$$

where $I_{c}$ and $I_{a}$ are, respectively, the crystalline and noncrystalline integrated intensities. 


\subsubsection{Atomic Force Microscopy (AFM)}

\subsubsection{Roughness parameters}

The topographic analysis of the biofilms was performed using an Atomic Force Microscope (AFM) Nanosurf EasyScan 2 controller in contact mode, with silicon cantilever ContAL-G having a resonance frequency of $13 \mathrm{kHz}$ and elastic constant of $0.2 \mathrm{~N} / \mathrm{m}$. The samples were fixed on the sample holder with double-sided tape.

The region of analysis was of $30^{\mu} \mathrm{m}^{2}$, with a scan rate of 0.7 seconds per line and a contact force of $19.2 \mathrm{nN}$. Twenty images were taken of each sample to obtain a more representative average of the medium roughness $R_{M}$, and root-mean-square roughness $\mathrm{R}_{\mathrm{RMS}}$, which are obtained using Equation 2 and Equation 3, respectively.

$$
R_{m}=\iint|Z(x, y)| d x . d y
$$

where $R_{M}$ is medium roughness evaluated on the entire surface, and $\mathrm{Z}(\mathrm{x}, \mathrm{y})$ is the height function of the vertical profile.

$$
R_{R M S}=\sqrt{|Z(x, y)|^{2} d x \cdot d y}
$$

where $R_{\text {RMS }}$ is the Root Mean Square Roughness ${ }^{[28]}$, and both parameters were determined by the software WSxM 5.0 version (Nanotec Eletronica S. L.).

\subsubsection{Topographic homogeneity}

In order to obtain the superficial entropy of biofilms, an algorithm developed in $\mathrm{R}$ language was used, as in our previous works (for more details see, e. $g^{[3,24]}$ ). This algorithm considers that the surface entropy can be calculated from a height matrix that was provided by AFM images. The WSXM software was used to convert the pixels of the AFM images to binary images of heights. The uniform patterns of biofilms were studied as parameters because they represent the uniformity of the surface, based on its height distribution.

The algorithm was developed to consider this matrix with an NxN dimension. Thus, Shannon entropy was used to determine uniform and non-uniform height patterns related to the binary matrix, using Equation $4^{[29]}$ :

$$
H^{(2)}=-\sum_{i=1}^{N} \sum_{j=1}^{N} p_{i j} \log p_{i j}
$$

where, $p_{i j}$ is the array that converts each pixel value to height. After that, the algorithm normalized the values to find the patterns so that the normalized entropy value varies from 0 to 1 using a normalization obtained by Equation 5:

$$
H_{\text {matr alt }}=\frac{H^{(2)}-H_{\text {min }}^{(2)}}{H_{\text {max }}^{2}-H_{\text {min }}^{(2)}}
$$

where $H_{\max }^{(2)}$ represents the surface with minimum uniform patterns and $H_{\min }^{(2)}$ represents the non-uniform pattern surface. We focused our analysis only on the uniform $H_{\max }^{(2)}$ standard values below represented only by the letter $\mathrm{H}$. It is also worth highlighting that this algorithm is not commercially provided.

\subsubsection{Advanced fractal analysis}

The complexity of a surface can reveal patterns of surface texture. When this parameter is combined with other parameters such as percolation and gap distribution, it can be a powerful tool for analyzing the fractal behavior of a surface.

Fractal characterization was performed by calculating the fractal dimension $\left(\mathrm{F}_{\mathrm{D}}\right)$, fractal succolarity $\left(\mathrm{F}_{\mathrm{S}}\right)$, and fractal lacunarity $\left(\mathrm{F}_{\mathrm{L}}\right)$. Fractal dimension is a parameter linked to surface texture and is related to texture homogeneity, as well as fractal lacunarity. However, percolation is related to the homogeneity of fluid entry over the surface texture.

$F_{D}$ was measured using the free software Gwyddion 2.47. Fractal succolarity was calculated using the same binary matrices used in the calculation of surface entropy. The adopted procedure was the same one carried out in our previous works, see, e.g ${ }^{[24]}$. In summary, according to Melo and Conci $^{[30]}$ it is necessary to use Equation 6.

$$
F S(T(k), \text { dir })=\frac{\sum_{k=1}^{n} P_{0}\left(T(k) \cdot P R\left(T(k), p_{c}\right)\right.}{\sum_{k=1}^{n} P R\left(T(k), p_{c}\right)}
$$

where dir is the water inlet direction, $\mathrm{PR}$ is the occupation pressure, $T(k)$ is boxes of equal sizes $T(n), p c$ is the position of the centroid $(\mathrm{x}, \mathrm{y})$ of pressure applied to the calculated box, and $\operatorname{Po}(\mathrm{T}(\mathrm{k}))$ is the occupation percentage. The $\mathrm{F}_{\mathrm{S}}$ and $\mathrm{F}_{\mathrm{L}}$ were calculated using an algorithm developed by our group (see, e.g., ${ }^{[24]}$ ). For the calculation of $\mathrm{F}_{\mathrm{L}}$, the Box-Counting-Differential algorithm ${ }^{[31]}$ was adapted for the programming language FORTRAN $77^{[22]}$. Moreover, the same binary matrices were used. The box containing small squares depends on the sample size and has been denoted $\mathrm{r}$ x r. The Equation 6 then calculates the lacunarity for the box size:

$$
L(r)=\frac{M 2}{[M 1]^{2}}
$$

where $M 1=\sum s P(s, r)$ and $M 2=\sum s^{2} P(s, r)$ are the first and second moments of the distribution $\mathrm{P}(\mathrm{s}, \mathrm{r})$, respectively. Fractal lacunarity decreases with increasing the size $r$ of the selected box, according to the power-law of the Equation $7^{[22]}$ :

$$
L(r)=\alpha r^{\beta}
$$

where the exponent $\beta<0$ can be estimated as the angular coefficient of the $\log [\mathrm{L}(\mathrm{r})]$ versus $\log (\mathrm{r})$ curve. The analysis of microtexture homogeneity was focused on $\beta$ beta, which is the quantitative parameter of fractal lacunarity.

\subsubsection{Scanning Electron Microscopy (SEM)}

The film morphology was evaluated using scanning electron microscopy (SEM) with a JEOL 5700 microscope. The samples were previously coated with gold, and the images were obtained with an accelerating voltage of $10 \mathrm{kV}$.

\subsubsection{Statistical analysis}

Analyses of variance (ANOVA) were carried out $(\mathrm{p}<0.05)$ to evaluate significant differences between the means for the topographic and fractal parameters. The analyzes were based on twenty different measurements. The Tukey test was applied to discriminate differences between treatments when necessary using OriginPro ${ }^{\circ} 8.0$ software (trial version). 


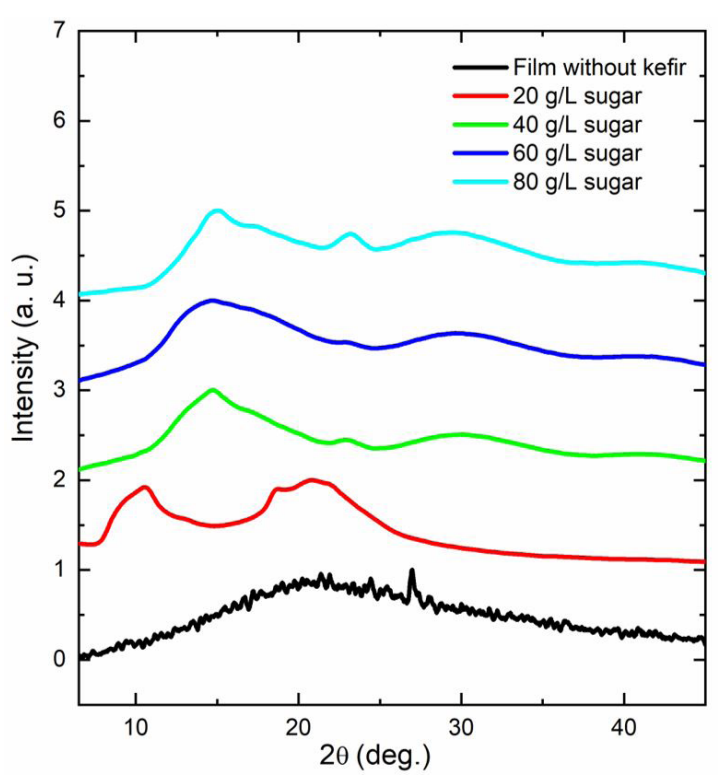

Figure 1. XRD patterns of the control film and biofilms grown with kefir in white sugar subtract.

\section{Results and Discussion}

\subsection{XRD Analysis}

The influence of the white sugar on the crystalline structure of the biofilm was investigated by XRD analysis. The XRD patterns of the control film and biofilms prepared with sugar concentrations of 20 g.L. ${ }^{-1}, 40$ g.L.- ${ }^{-1}, 60$ g.L. L $^{-1}$ and 80 g. $\mathrm{L}^{-1}$ are shown in Figure 1. All XRD patterns are typical of amorphous-crystalline structure. The Kefir biofilms prepared with a sugar concentration of 20 g.L.-1 exhibited four diffraction broad peaks at $2 \theta \approx 10.45^{\circ}, 12.83^{\circ}, 18.71^{\circ}$, and $20.90^{\circ}$. However, XRD peaks intensities decreased as the concentration of sugar in the films was increased from $40 \mathrm{~g} . \mathrm{L}^{-1}$ to $80 \mathrm{~g} . \mathrm{L}^{-1}$, indicating that the introduction of sucrose into water kefir EPS induces a decrease in crystallinity. Further, it is also observed that reflection peak at $2 \theta \approx 12.83^{\circ}$ disappeared and other additional low-intensity peaks are observed at $2 \theta \approx 30.13^{\circ}$ and $42.16^{\circ}$ for sugar concentration higher than 40 g. $\mathrm{L}^{-1}$. Moreover, a comparison of the XRD patterns shows that the angles of the diffraction peaks were not noticeably shifted toward a higher angle and broadened for the biofilms prepared with sugar concentration
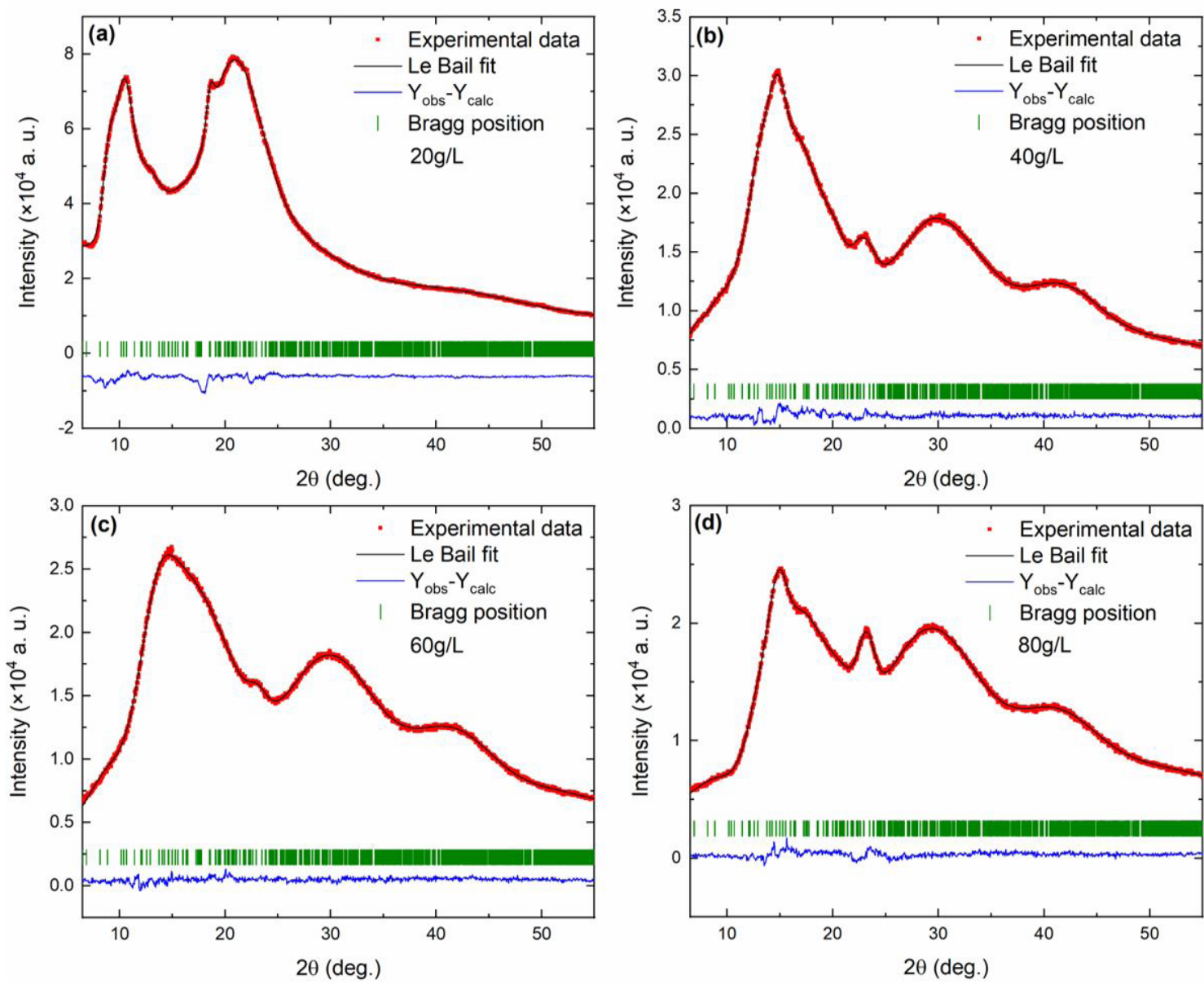

Figure 2. Le Bail refined XRD pattern of kefir biofilms prepared with sugar concentrations of (a) 20 g.L $\mathrm{L}^{-1}$, (b) 40 g.L. ${ }^{-1}$, (c) 60 g.L ${ }^{-1}$ and (d) 80 g.L $\mathrm{L}^{-1}$. 
higher than $20 \mathrm{~g} . \mathrm{L}^{-1}$. This can probably indicate increases in the formation of chain regularity in amorphous regions and a decrease in the degree of crystallinity.

The XRD peaks indexing were performed with the program McMaille ${ }^{[32]}$, which gives the monoclinic system ( $P 12_{1} / c 1$ space group) with $\mathrm{a} \approx 10.86 \AA, \mathrm{b} \approx 14.59 \AA, \mathrm{c} \approx 27.48 \AA$, and $\alpha=\beta=\gamma=90^{\circ}$ and a factor of merit ranging from 20 to 30 . This information was selected as the starting model structure for the Le Bail Rietveld refinement of the observed X-ray diffraction profile. The XRD pattern and the corresponding Le Bail refinement result for the Kefir biofilms are shown in Figure 2. Le Bail refinements yielded an acceptable result $\left(\chi^{2} \approx 1.5-2.0\right)$ and confirmed a significant increasing of the sample amorphous character as sugar concentration is increased from 20 g.L.- to 80 g.L $\mathrm{L}^{-1}$, as given in Table 1.

Furthermore, it is also possible to see that the crystallinity percentage decreased almost linearly for sugar concentrations between 20 g.L. $\mathrm{L}^{-1}$ and 60 g.L $\mathrm{L}^{-1}$, indicating that intramolecular and intermolecular bonds of the Kefir structure are weakened as the sugar concentration increases. However, there was a drastic decrease when the concentration was between 60 g.L $\mathrm{L}^{-1}$ and 80 g. $\mathrm{L}^{-1}$. This suggests that there was a saturation of the formation of crystalline phases, which can be associated with the formation of the biofilm. Furthermore, it worth mentioning the uncontrolled character of biofilm growth as a consequence of the random process of formation from in vivo biofilm ${ }^{[33]}$.

The obtained results show that Kefir biofilms cultivated in white sugar have excellent flexibility indicating the semi-crystalline character of these materials ${ }^{[34]}$. In general, a crystalline partial behavior of the biofilms is observed when white sugar concentrations are between 20 g.L $\mathrm{L}^{-1}$ and 60 g.L $L^{-1}$ (Table 1). Furthermore, our results also indicate that biofilms structure is relatively balanced, containing amorphous and crystalline phases (57.5 against 42.5\%), especially for 20 g.L. - $^{-1}$ concentration. These results are quite close to that previously reported by Matos et al. ${ }^{[3]}$ for kefir biofilms grown in brown sugar solutions.

Therefore, our results suggest that the kefir biofilms grown in white sugar have a structure similar to that of biofilms grown in brown sugar solutions. However, the presence of more crystalline phases was observed, which was not seen in the study of Matos et al. ${ }^{[3]}$ and Ghasemlou et al. ${ }^{[21]}$. This result shows that white sugar altered the crystalline structure of biofilms, mostely in the biofilms prepared using lower sugar concentrations. Microorganisms probably consume sugar more quickly at low concentrations and secrete a more crystalline EPS matrix. Thus, one of the causes of the emergence of such phases would be the strengthening of the intramolecular and intermolecular bonds of the biofilm, whose characteristic is very similar to one of the polymers, which spreads the potentiality of application of this material.

\subsection{AFM and Advanced fractal analysis}

Recently, several researchers such as Ghanbarzadeh and Oromiehie ${ }^{[35]}$, Bergo et al. ${ }^{[36]}$, Ghasemlou et al. ${ }^{[21]}$ and Matos et al. ${ }^{[3]}$ have studied films or biofilms with some biotechnological applications such as food packaging and biocurative. However, only in the last two studies, the surfaces characteristics of these films were evaluated by
Table 1. Crystallographic profile of the kefir biofilms cultivated in white sugar and control film.

\begin{tabular}{lll}
\hline \multicolumn{1}{c}{ Concentration } & Crystallinity (\%) & Amorphicity (\%) \\
\hline $\begin{array}{l}\text { Control Film } \\
40 \text { g.L }{ }^{-1}\end{array}$ & 0.1 & \\
Kefir Biofilms & & 99.9 \\
20 g.L.- & 42.5 & 57.5 \\
40 g.L. & 34.5 & 65.5 \\
60 g.L. $\mathrm{L}^{-1}$ & 29.6 & 70.4 \\
80 g. $L^{-1}$ & 0.5 & 99.5 \\
\hline
\end{tabular}
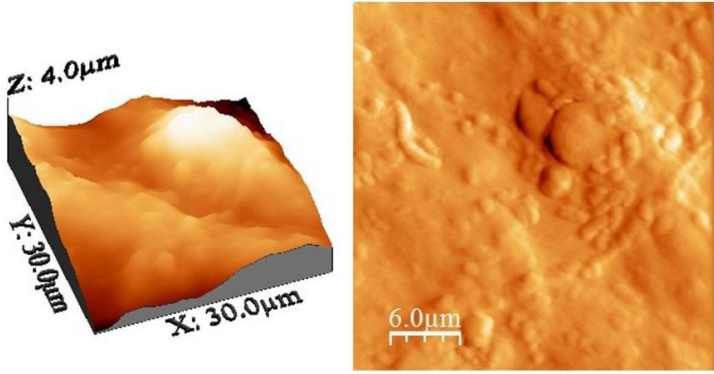

Figure 3. Topographic Images of $3 \mathrm{D}$ deflexion (left) and 2D deflexion (right) of the film without kefir. The surface details presented some trace of microorganisms.

AFM. Therefore, considering that topographic analysis can reveal many morphologic characteristics of the materials, in this work, we studied surface adhesion using topographic parameters such as roughness and surface entropy.

Figure 3 shows both 3D and 2D (deflection) AFM images of the control film obtained in this analysis. The 3D images show the behavior of the peak distribution in the sample and help to understand the roughness parameter.

On the other hand, the biofilms of kefir grown in white sugar present an abundance of microorganism of the microbiota of kefir grains, as presented in the topographic images of AFM, Figure 4. As can be seen, between 20 g.L $\mathrm{L}^{-1}$ and $40 \mathrm{~g} . \mathrm{L}^{-1}$ samples, there is more abundance of lactobacilli and between 60 g.L. $\mathrm{L}^{-1}$ and 80 g.L. $\mathrm{L}^{-1}$, more yeasts. The presence of these microorganisms in biofilms was expected because the kefir microbiota is formed mostly by lactobacilli and yeasts. A similar result was found by Almeida et al. ${ }^{\left[{ }^{[7]}\right.}$ for kefir biofilms prepared with Açaí extract. This fact is fundamental for the analysis of the biotechnological applicability of biofilms.

The quantitative parameters related to the topographic irregularities of the biofilms are displayed in Table 2. The statistical analysis through Tukey test revealed that only kefir biofilms with 60 g.L. ${ }^{-1}$ and 80 g.L. $\mathrm{L}^{-1}$ had $\mathrm{R}_{\mathrm{RMS}}$ and $\mathrm{R}_{\mathrm{m}}$ significant compared to control film. This means that higher concentrations of sugar affected the film roughness. However, no statistical difference was found among the kefir biofilms.

These analyzes showed that all biofilms with kefir are relatively similar to the one found by Matos et al. ${ }^{[3]}$ to biofilms with brown sugar. However, microbiologically, the surface of the control film presents traces of some microorganisms that should not exist. Technically, as already mentioned they can be microorganisms that emerge as result of bacteria resulting from the artisanal fabrication process of sugar or 

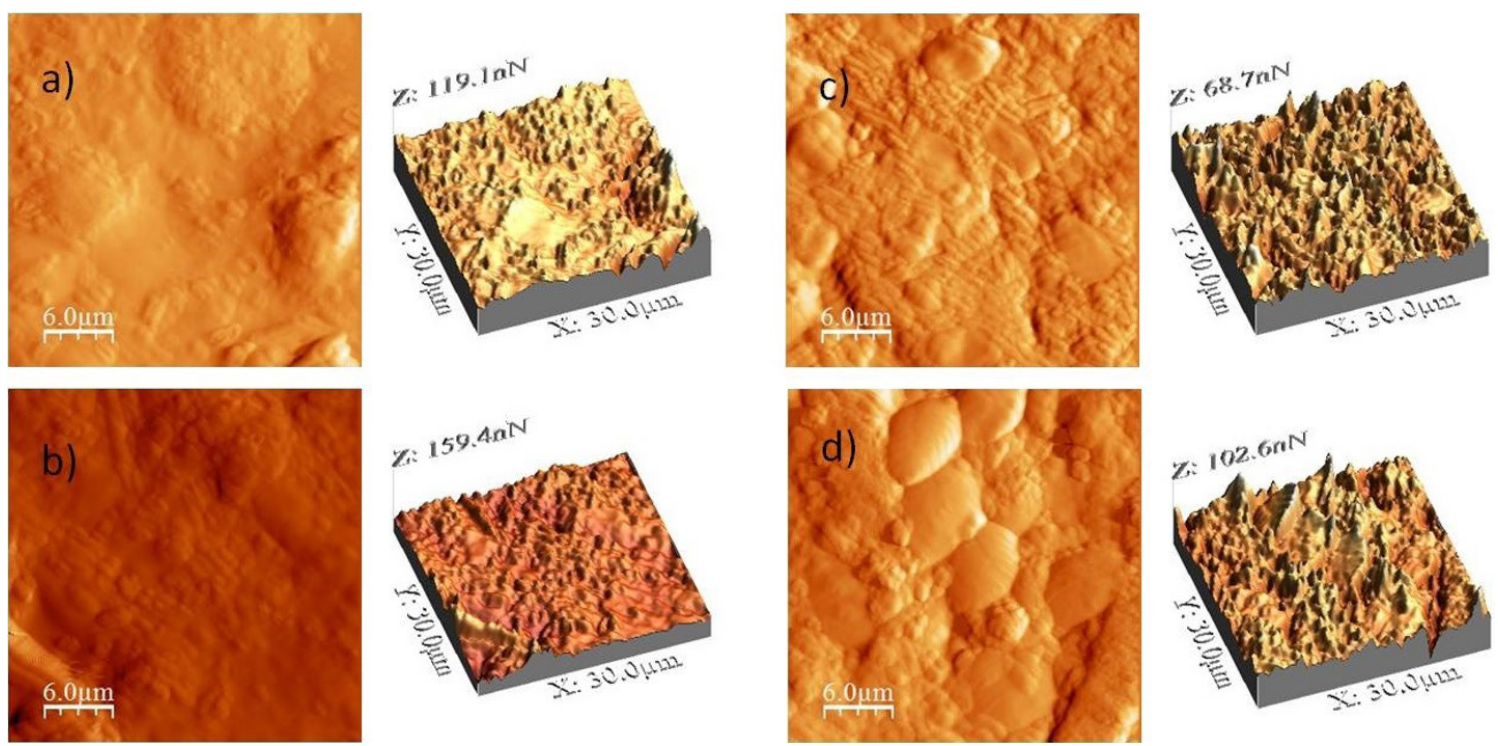

Figure 4. Topographic images of 2D deflexion (left) and 3D deflexion (right) with four different concentrations of white sugar: (a) 20 g.L $L^{-1}$, (b) 40 g.L - $^{-1}$, (c) 60 g.L -1 $^{-1}$ (d) 80 g.L L $^{-1}$.

Table 2. Mean values of roughness parameters and topographic homogeneity obtained from atomic force microscopy images; $\mathrm{R}_{\mathrm{M}}, \mathrm{R}_{\mathrm{RMS}}$, and $\mathrm{H}$. The average results were expressed as mean value and standard deviation.

\begin{tabular}{lccc}
\hline Concentration & $\boldsymbol{R}_{\boldsymbol{M}}(\boldsymbol{n m})$ & $\boldsymbol{R}_{\boldsymbol{R M S}}(\boldsymbol{n m})$ & $\boldsymbol{H}$ \\
\hline Control Film & & & \\
40 g.L. & $327.234 \pm 99.100$ & $412.670 \pm 101.700$ & $0.988 \pm 0.004$ \\
Kefir Biofilms & & & \\
20 g.L $\mathrm{L}^{-1}$ & $406.955 \pm 123.700$ & $509.030 \pm 155.100$ & $0.982 \pm 0.019$ \\
40 g.L $\mathrm{L}^{-1}$ & $395.625 \pm 99.500$ & $499.010 \pm 125.200$ & $0.975 \pm 0.021$ \\
60 g.L $\mathrm{L}^{-1}$ & $482.755 \pm 150.300$ & $600.760 \pm 179.900$ & $0.980 \pm 0.023$ \\
80 g.L. & $480.305 \pm 108.200$ & $598.865 \pm 136.400$ & $0.985 \pm 0.023$ \\
\hline
\end{tabular}

Table 3. Mean values (and standard deviation) of FD, FS and $\beta$ obtained from atomic force microscopy images. The average results were expressed as mean value and standard deviation.

\begin{tabular}{lccc}
\hline Concentration & $\boldsymbol{F}_{\boldsymbol{D}}$ & $\boldsymbol{F}_{\boldsymbol{S}}$ & $\boldsymbol{a}$ \\
\hline Control Film & & & \\
$40 \mathrm{~g} . \mathrm{L}^{-1}$ & $2.450 \pm 0.045$ & $0.689 \pm 0.082$ & $0.078 \pm 0.010$ \\
Kefir Biofilm & & & \\
$20 \mathrm{~g} . \mathrm{L}^{-1}$ & $2.310 \pm 0.087$ & $0.536 \pm 0.031$ & $0.058 \pm 0.008$ \\
$40 \mathrm{~g} . \mathrm{L}^{-1}$ & $2.370 \pm 0.046$ & $0.531 \pm 0.049$ & $0.067 \pm 0.010$ \\
$60 \mathrm{~g} . \mathrm{L}^{-1}$ & $2.420 \pm 0.033$ & $0.516 \pm 0.046$ & $0.057 \pm 0.009$ \\
$80 \mathrm{~g} . \mathrm{L}^{-1}$ & $2.430 \pm 0.040$ & $0.532 \pm 0.034$ & $0.058 \pm 0.010$ \\
\hline
\end{tabular}

when there is improper storage of the product, once it is commercial brow sugar. In Matos et al. ${ }^{[3]}$, where the brown sugar concentration was kept constant at 40 g. $\mathrm{L}^{-1}$, and the kefir concentration was varied, the lower value to roughness found was $671.515 \mathrm{~nm}$, while in the study presented it was $499.010 \pm 125.200 \mathrm{~nm}$. This result is too slightly higher than those found by Ghasemlou et al. ${ }^{[21]}$ for kefiran film.

This high roughness value is considered a positive factor for surface adhesion because according to Kantorsk and Pagani ${ }^{[38]}$ high roughness is associated with excellent adhesiveness. Likewise, high topographic uniformity $(\mathrm{H} \sim 1)$ contributes to good uniformity of the surface adhesion. Moreover, Matos et al. ${ }^{[3]}$ have already shown that kefir biofilms that have high surface uniformity would not allow the formation of bubbles when adhered to some surface, reflecting on the interaction of these biofilms with the human skin, like a potential application of these biofilms as natural curatives. Another important conclusion is that sugar concentration does not affect surface homogeneity. Biofilms with high surface uniformity were previously reported, e. $g^{[3,39]}$. However, most important is the fact that the biofilms displayed microorganisms deposited on the surface, which can be considered excellent for their applicability, in addition to topographic parameters whose values suggest good wettability and surface adhesion.

Kefir microbiota is mainly composed of bacteria of the genus Lactobacillus ${ }^{[40,41]}$ and yeasts ${ }^{[42]}$. Lactobacillus has a cylindrical and elongated shape, while the yeasts usually are blastoconidium shaped ${ }^{[38]}$. Thus, from the Figure 4 it can be seen that the emergence of yeasts are more evident at the sugar concentrations of 60 (Figure $4 \mathrm{c}$ ) and 80 g.L L $^{-1}$ (Figure 4d) while Lactobacillus is most observed in 20 (Figure $4 \mathrm{a}$ ) and 40 g.L $\mathrm{L}^{-1}$ (Figure $4 \mathrm{~b}$ ). This can be explained by the fact that an increase in sugar concentration increases fermentation in the sample, which makes the environment conducive to the growth of yeasts. This same behavior was observed by Domingues et al. ${ }^{[43]}$ for sugar cane, from where commercial sugar is derived. Thus, at low concentrations, Lactobacillus can rapidly consume the sugar, preventing the abundant growth of the yeasts.

Regarding spatial complexity of the biofilms, the Table 3 shows the values related to the three fractal parameters studied. The Tukey test revealed that $\mathrm{F}_{\mathrm{D}}$ of kefir biofilms with 60 and 80 g.L $\mathrm{L}^{-1}$ was no significant in relation to control film. These higher concentrations showed greater spatial complexities (major irregularities). Hence, kefir biofilms with 20 and 40 g.L. $\mathrm{L}^{-1}$ exhibited lesser spatial complexities. 
For FS, Tukey test showed that all kefir biofilms were significant in relation to control film. However, between kefir biofilms there was no significant difference, indicating that kefir biofilms prepared with white sugar have similar permeability. Likewise, lacunarity coefficient $\beta$ was significant for all kefir biofilms in relation to control film. The control film presented the highest $\beta$, with the most heterogeneous surface texture. However, among biofilms, only the biofilm with $40 \mathrm{~g} . \mathrm{L}^{-1}$ had $\beta$ significant in relation to the others. As this concentration exhibited one of the highest $\beta$ values (Table 3 ), this biofilm had the least homogeneous texture. Therefore, the films that exhibited the most uniform textures had 20,60, and 80 g.L. $\mathrm{L}^{-1}$ of white sugar.

Fractal analyses confirmed (along with the roughness value) the increase in complexity of patterns existing in the nanotexture of the biofilms. Moreover, the fractal succolarity values did not present significant differences between biofilms, showing that the white sugar concentration does not influence the degree of water penetration on the biofilms' surface. These statistical results prove that all biofilms have approximate surface percolation, suggesting that the variation in the white sugar concentration does not influence the surface porosity. However, fractal lacunarity did not exhibit a consistent pattern of nanotexture homogeneity according to the increase in sugar concentration in the biofilm structure. This fact can be explained by the high randomness of the formation of membranes in vivo because the mechanisms of the formation of biofilms depend of others factors, in addition to the availability of energy for microbial development.

Furthermore, Israelachvili ${ }^{[33]}$ emphasizes that the in vivo membrane formation does not follow a predetermined pattern. This means that the formation of our biofilms was not a predominantly controlled event, which was to be expected because it was a development in natura. This occurred because they are biofilms produced with living microorganisms, which also justifies their high roughness value. This can also occur because of the increase of the coalescence in EPS matrix as a result of an increase in the sugar concentration once every living organism has its emulsifying system ${ }^{[44]}$ capable of changing the surface properties that makes it a more complex system.

Furthermore, it is possible to observe that the microorganisms are randomly arranged on the surface, as we look at Figure 4. In comparison to the XRD results, it is possible to notice that biofilms with high white sugar concentration have a better bacteria development and a better adhesiveness concerning film controlling. What seems more consistent is that biofilms produced with brown sugar develop better than biofilms with white sugar, as reported by Matos et al. ${ }^{[3]}$, where a better distribution of bacteria and yeasts in all samples was observed. Whether this potential curative can be produced, the difference between the commercial white sugar and brown sugar is the price because commercial white sugar has a lower price than brown sugar, which can cheapen the cost of this product. Although, this research reinforces the possibility of use, as natural dressings, of the kefir biofilms made in white sugar, having insight into his antibacterial activity, considering the maintenance of its antimicrobial potential by preferential deposition of microorganisms, mainly observed for sample with 20 g.L $\mathrm{L}^{-1}$.

\subsection{SEM analysis}

Figure 5 shows the most relevant SEM images obtained for the $20 \mathrm{~g} . \mathrm{L}^{-1}$ biofilms. The micrographs of this biofilm show structures similar to lactobacillus and yeast, corroborating the results described by AFM. The observed topography shows

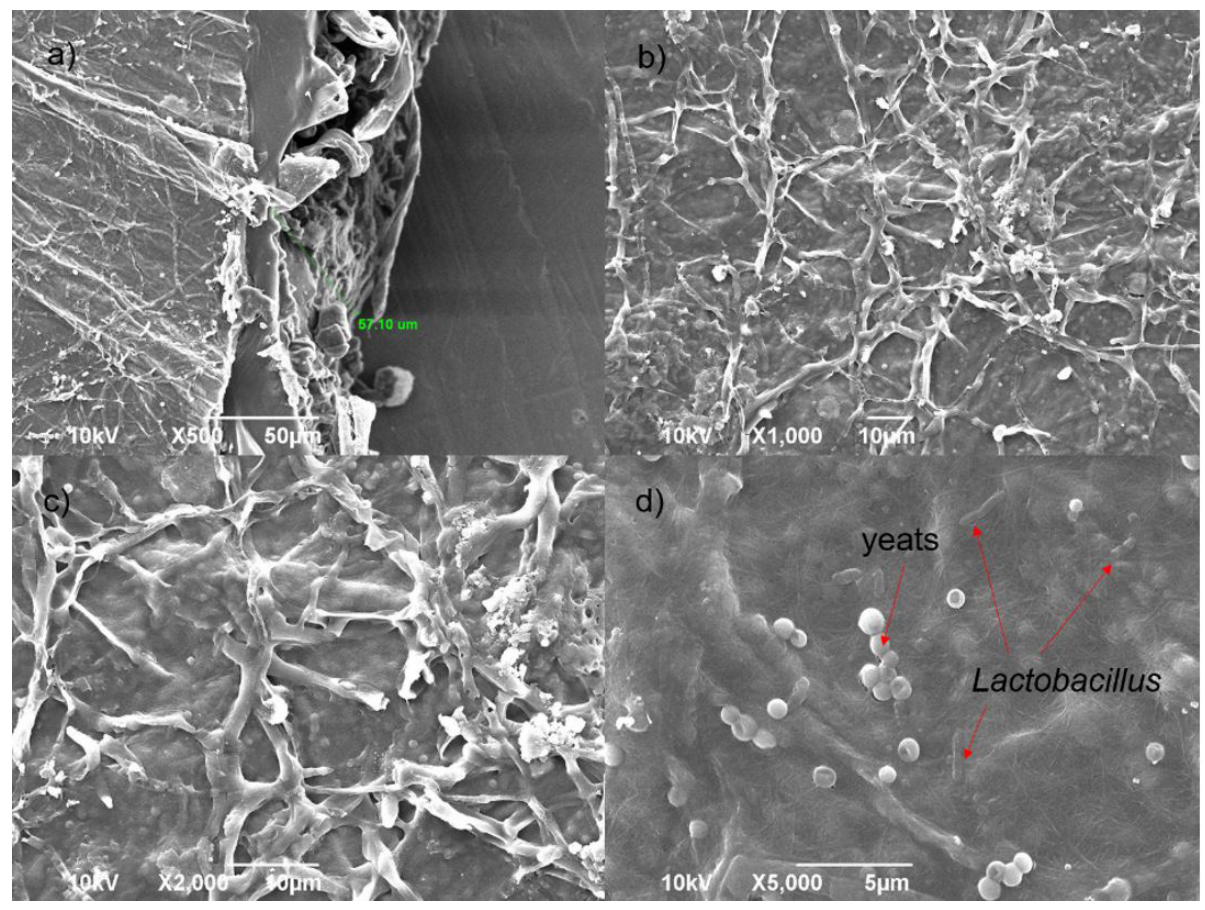

Figure 5. Transversal section SEM images of the 20 g. $\mathrm{L}^{-1}$ biofilm: (a) x500, (b) x1.000, (c) x2.000 and (d) x5.000. 
the presence of structures with apparent unfilled voids on the film's EPS matrix. Figure 5a shows details of the thickness of the biofilm obtained with an average value of $57.10 \mu \mathrm{m}$ which classifies it as a thin film, and Figure 5d shows the arrangement and shape of bacteria and yeast. Furthermore, Figure $5 \mathrm{~b}$ and $5 \mathrm{c}$ show how the microorganisms are tangled in the exopolysaccharide matrix.

These micrographs show microstructures similar to those obtained by Oliveira et al. ${ }^{[18]}$, where a random arrangement of the microorganisms on the exopolysaccharide matrix of the films was observed, which is a characteristic of the formation of polymicrobial films ${ }^{[45]}$. This fact, combined with the high roughness observed by AFM and high topographic uniformity, shows that surface adhesion is excellent and uniform. In addition, as there is biological activity on the surface, the interaction between the film and the surface of human skin will likely be beneficial. Considering the pharmacotherapeutic characteristics of kefir, the product generated by these biofilms may act fighting infections and accelerating the skin healing process. This is in agreement with what was discussed by Matos et al. ${ }^{[3]}$ and Oliveira et al. ${ }^{[17]}$, where both produced brown sugar kefir films and showed similar results.

It is important to report that kefiran-based films, which is the polysaccharide present in kefir grains, are highly hydrophilic ${ }^{[21]}$. This leads to high wettability that allows fluid and gas exchange with the surrounding environment. Moreover, this can help in cellular respiration when the film is acting as a bio-curative for human skin. Aditionally, it is essential to mention that the use of white sugar instead of brown sugar does not significantly affect the roughness, surface uniformity, and probable wettability of the biofilms.

\section{Conclusions}

In this research, we performed studies about the crystallography, topography, fractality, and morphology of kefir biofilms cultivated in commercial white sugar. XRD results demonstrated that the biofilms have a semi-crystalline structure for all the samples (crystallinity about 50\%), with resembling structure to other biopolymers like Kefiran. The topological analysis by AFM showed that the biofilms increased their roughness with increasing sugar concentration, indicating that samples have excellent adhesiveness. Surface morphologies presented structures similar to those of bacteria of Lactobacillus genus and yeasts distributed randomly in the samples. The randomness was confirmed with the measures of fractal parameters, where it was seen greater pattern complexity of texture in samples with higher sugar concentration, although a robust pattern of surface texture homogeneity has not been observed. SEM analysis confirmed the presence of microorganisms and microstructural details on the surface of the biofilm, showing that the symbiotic association of bacteria and yeast occurs throughout most of the film. All the results appoint that biofilms developed in the environment with white sugar have high roughness comparing to values referent to kefiran membrane, but less roughness compared to kefir biofilms grown in brown sugar. In addition, they can be used as natural dressings because their adhesiveness was relatively high, and the surface percolation was not affected by the increase of the white sugar concentration. Comparatively, biofilms produced with white sugar showed surface characteristics similar to those produced with brown sugar. Therefore, they can be a low-cost alternative of great interest for regenerative medicine using as a natural skin dressing.

\section{Acknowledgements}

The authors acknowledge the access to the experimental facilities at Drugs Research Laboratory of the Federal University of Amapá, Brazil. Ellen C. M. Gonçalves acknowledges the Research Department of the Federal University of Amapá, Brazil, for the scholarship. Nilson S Ferreira acknowledges Conselho Nacional de Desenvolvimento Científico e Tecnológico - CNPq for the financial support under grant No. 309054/2019-2.

\section{References}

1. Mao, A. S., \& Mooney, D. J. (2015). Regenerative medicine: current therapies and future directions. Proceedings of the National Academy of Sciences of the United States of America, 112(47), 14452-14459. http://dx.doi.org/10.1073/ pnas.1508520112. PMid:26598661.

2. Coma, M. E., Peltzer, M. A., Delgado, J. F., \& Salvay, A. G. (2019). Water kefir grains as an innovative source of materials: study of plasticiser content on film properties. European Polymer Journal, 120(109234), 1-9. http://dx.doi.org/10.1016/j. eurpolymj.2019.109234.

3. Matos, R. S., Lopes, G. A. C., Ferreira, N. S., Pinto, E. P., Carvalho, J. C. T., Figueiredo, S. S., Oliveira, A. F., \& Zamora, R. R. M. (2018). Superficial characterization of kefir biofilms associated with açaí and cupuaçu extracts. Arabian Journal for Science and Engineering, 43(7), 3371-3379. http://dx.doi. org/10.1007/s13369-017-3024-y,

4. Güzel-Seydim, Z. B., Seydim, A. C., Greene, A. K., \& Bodine, A. B. (2000). Determination of organic acids and volatile flavor substances in kefir during fermentation. Journal of Food Composition and Analysis, 13(1), 35-43. http://dx.doi. org/10.1006/jfca.1999.0842.

5. Garrote, G. L., Abraham, A. G., \& De Antoni, G. L. (2001). Chemical and microbiological characterization of kefir grains. The Journal of Dairy Research, 68(4), 639-652. http://dx.doi. org/10.1017/S0022029901005210. PMid:11928960.

6. Otles, S., \& Cagindi, O. (2003). Kefir: a probiotic dairycomposition, nutritional and therapeutic aspects. Pakistan Journal of Nutrition, 2(2), 54-59. http://dx.doi.org/10.3923/ pjn.2003.54.59.

7. Pogačić, T., Šinko, S., Zamberlin, Š., \& Samaržija, D. (2013). Microbiota of kefir grains. Mljekarstvo, 63(1), 3-14. http:// dx.doi.org/10.3923/pjn.2003.54.59.

8. Radhouani, H., Bicho, D., Gonçalves, C., Maia, F. R., Reis, R. L., \& Oliveira, J. M. (2019). Kefiran cryogels as potential scaffolds for drug delivery and tissue engineering applications. Materials Today Communications, 20(100554), 1-6. http:// dx.doi.org/10.1016/j.mtcomm.2019.100554.

9. Radhouani, H., Gonçalves, C., Maia, F. R., Oliveira, J. M., \& Reis, R. L. (2018). biological performance of a promising kefiran-biopolymer with potential in regenerative medicine applications: a comparative study with hyaluronic acid. Journal of Materials Science. Materials in Medicine, 29(124), 1-10. http://dx.doi.org/10.1007/s10856-018-6132-7. PMid:30051294.

10. Blandón, L. M., Islan, G. A., Castro, G. R., Noseda, M. D., Thomaz-Soccol, V., \& Soccol, C. R. (2016). Kefiran-alginate gel microspheres for oral delivery of ciprofloxacin. Colloids 
and Surfaces. B, Biointerfaces, 145(1), 706-715. http://dx.doi. org/10.1016/j.colsurfb.2016.05.078. PMid:27289312.

11. Dadashi, S., Boddohi, S., \& Soleimani, N. (2019). Preparation, characterization, and antibacterial effect of doxycycline loaded kefiran nanofibers. Journal of Drug Delivery Science and Technology, 52, 979-985. http://dx.doi.org/10.1016/j. jddst.2019.06.012.

12. Vu, B., Chen, M., Crawford, R. J., \& Ivanova, E. P. (2009). Bacterial extracellular polysaccharides involved in biofilm formation. Molecules (Basel, Switzerland), 14(7), 2535-2554. http://dx.doi.org/10.3390/molecules14072535. PMid:19633622.

13. Stoodley, P., Sauer, K., Davies, D. G., \& Costerton, J. W. (2002). Biofilms as complex differentiated communities. Annual Review of Microbiology, 56(1), 187-209. http://dx.doi.org/10.1146/ annurev.micro.56.012302.160705. PMid:12142477.

14. Caixeta, D. S., Scarpa, T. H., Brugnera, D. F., Freire, D. O., Alves, E., Abreu, L. R. D., \& Piccoli, R. H. (2012). Chemical sanitizers to control biofilms formed by two Pseudomonas species on stainless steel surface. Food Science and Technology (Campinas), 32(1), 142-150. http://dx.doi.org/10.1590/S010120612012005000008.

15. Carpentier, B., \& Cerf, O. (1993). Biofilms and their consequences, with particular reference to hygiene in the food industry. The Journal of Applied Bacteriology, 75(6), 499-511. http://dx.doi. org/10.1111/j.1365-2672.1993.tb01587.x. PMid:8294303.

16. Simões, M., Simões, L. C., \& Vieira, M. J. (2010). A review of current and emergent biofilm control strategies. LebensmittelWissenschaft \& Technologie-Food Science and Techonology, 43(4), 573-583. http://dx.doi.org/10.1016/j.lwt.2009.12.008.

17. Oliveira, A. F., Santos, C. B. R., Ferreira, A. M., Bezerra, R. M., Zamora, R. R. M., Cruz, R. A. S., Amado, J. R. R., \& Carvalho, J. C. T. (2017). A viability study for the production of biofilms and in silico predictions of major compounds in kefir. Journal of Computational and Theoretical Nanoscience, 14(6), 2915-2926. http://dx.doi.org/10.1166/jctn.2017.6594.

18. Oliveira, A. F., Maciel, A. F., Florentino, A. C., Fernandes, C. P., Bezerra, R. M., Góes, M. B., Salcedo, M. O. C., Zamora, R. R. M., \& Carvalho, J. C. T. (2017). Study of kefir biofilm aassociated with hydroethanolic extract of Euterpe oleracea Mart.(aai). African Journal of Microbiological Research, 11(39), 1474-1483. http://dx.doi.org/10.5897/AJMR2017.8622.

19. Mendonça, C. R., Rodrigues, R. S., \& Zambiazi, R. C. (2000). Açúcar mascavo em geleiadas de maçã. Ciência Rural, 30(6), 1053-1058. http://dx.doi.org/10.1590/S0103-84782000000600022.

20. Bettani, S. R., Lago, C. E., Faria, D. A. M., Borges, M. T. M. R., \& Verruma-Bernardi, M. R. (2014). Avaliação físicoquímica e sensorial de açúcares orgânicos e convencionais. Revista Brasileira de Produtos Agroindustriais, 16(2), 155-162. http://dx.doi.org/10.15871/1517-8595/rbpa.v16n2p155-162.

21. Ghasemlou, M., Khodaiyan, F., \& Oromiehie, A. (2011). Rheological and structural characterization of film-forming solutions and biodegradable edible film made from kefiran as affected by various plasticizer types. International Journal of Biological Macromolecules, 49(4), 814-821. http://dx.doi. org/10.1016/j.ijbiomac.2011.07.018. PMid:21827782.

22. Salcedo, M. O. C., Zamora, R. R. M., \& Carvalho, J. C. T. (2016). Estudio fractal de la superficie de la hoja de la especie vegetal copaifera sp. haciendo uso del microscopio de Fuerza Atómica-AFM. Revista ECIPerú, 13(1), 1-7. http://dx.doi. org/10.33017/RevECIPeru2016.0002.

23. Alburquerque, M. P. (2000). Processamento de Imagens: métodos e análises. Rio de Janeiro: Centro Brasileiro de Pesquisas Físicas. Retrieved in 2020, April 4, from http:// www.cbpf.br/cat/pdsi/pdf/processamentoimagens.pdf

24. Ştefan, Ţ., Abdolghaderi, S., Pinto, E. P., Matos, R. S., \& Salerno, M. (2020). Advanced fractal analysis of nanoscale topography of Ag/DLC composite synthesized by RF-PECVD. Surface Engineering, 36(7), 713-719. http://dx.doi.org/10.10 80/02670844.2019.1710937.

25. Le Bail, A., Duroy, H., \& Fourquet, J. L. (1988). Ab-initio structure determination of LiSbWO6 by X-ray powder diffraction. Materials Research Bulletin, 23(3), 447-452. http:// dx.doi.org/10.1016/0025-5408(88)90019-0.

26. Carvajal, J. R. (2001). Recent developments of the program FULLPROF, in commission on powder diffraction (IUCr). Newsletter, 26, 12-19.

27. Stern, P. G., \& Segerman, E. (1968). On the structure of polypropylene fibres. Polymer, 9, 471-477. http://dx.doi. org/10.1016/0032-3861(68)90057-8.

28. Khulbe, K. C., Feng, C., \& Matsuura, T. (2008). synthetic polymeric membranes: characterization by atomic force microscopy. USA: Springer. http://dx.doi.org/10.1007/9783-540-73994-4.

29. Nosonovsky, M. (2010). Entropy in tribology: in the search for applications. Entropy (Basel, Switzerland), 12(6), 1345-1390. http://dx.doi.org/10.3390/e12061345.

30. Melo, R. H. C., \& Conci, A. (2008). Succolarity: defining a method to calculate this fractal measure. In Proceedings of the 15th International Conference on Systems, Signals and Image Processing (pp. 291-294). USA: IEEE. http://dx.doi. org/10.1109/iwssip.2008.4604424.

31. Mandelbrot, B. (1983). The fractal geometry of nature. New York: W. H. Freeman and company. http://dx.doi.org/10.1119/1.13295.

32. Le Bail, A. (2004). Monte carlo indexing with McMaille. Powder Diffraction, 19(3), 249-254. http://dx.doi.org/10.1154/1.1763152.

33. Israelachvili, J. N. (2011). Intermolecular and surface forces. Cambridge: Academic Press.

34. Coutinho, F. M. B., Mello, I. L., \& Santa Maria, L. C. (2003). Polietileno: principais tipos, propriedades e aplicações. Polímeros: Ciência e Tecnologia, 13(1), 1-13. http://dx.doi. org/10.1590/S0104-14282003000100005.

35. Ghanbarzadeh, B., \& Oromiehi, A. R. (2008). Biodegradable biocomposite films based on whey protein and zein: barrier, mechanical properties and AFM analysis. International Journal of Biological Macromolecules, 43(2), 209-215. http://dx.doi. org/10.1016/j.ijbiomac.2008.05.006. PMid:18619671.

36. Bergo, P., Sobral, P. J. A., \& Prison, J. M. J. (2010). Effect of Glycerol on Physical Properties of Cassava Starch Films. Journal of Food Processing and Preservation, 34(s2), 401-410. http://dx.doi.org/10.1111/j.1745-4549.2008.00282.x.

37. Almeida, A. P., Pinto, E. P., Santos, P. G. P., Filho, H. D. F., \& Matos, R. S. (2019). Distribution of microorganisms on surface of kefir biofilms associated with açaí extract. Scientia Amazônia, 8(3), 10-18.

38. Kantorsk, K. Z., \& Pagani, C. (2007). Influência da rugosidade superficial dos materiais odontológicos na adesão bacteriana: revisão de literatura. Revista Brasileira de Odontologia, 19(3), 325-330. http://dx.doi.org/10.1016/j.ijbiomac.2008.05.006.

39. Pinto, E. P., Tavares, W. S., Matos, R. S., Ferreira, A. M., Menezes, R. P., Costa, M. E. H. M., Souza, T. M., Ferreira, I. M., Sousa, F. F. O., \& Zamora, R. (2018). Influence of low and high glycerol concentrations on wettability and flexibility of chitosan biofilms. Quimica Nova, 41(10), 1109-1116. http:// dx.doi.org/10.21577/0100-4042.20170287.

40. Dias, P. A., Rosa, J. V., Tejada, T. S., \& Timm, C. D. (2016). Propriedades antimicrobianas do kefir. Arquivos do Instituto Biológico, 83(e0762013), 1-5. http://dx.doi.org/10.1590/18081657000762013 .

41. Bosch, A., Golowczyc, M. A., Abraham, A. G., Garrote, G. L., De Antoni, G. L., \& Yantorno, O. (2006). Rapid discrimination of lactobacilli isolated from kefir grains by FT-IR spectroscopy. 
International Journal of Food Microbiology, 111(3), 280287. http://dx.doi.org/10.1016/j.ijfoodmicro.2006.05.010. PMid:16860422.

42. Talaro, K. P. E. (2002). Foundations in microbiology. New York: Mc Graw-Hill.

43. Domingues, F. N., Oliveira, M. D. S., Siqueira, G. R., Roth, A. P. T. P., Santos, J., \& Mota, D. A. (2011). Estabilidade aeróbia, $\mathrm{pH}$ e dinâmica de desenvolvimento de microrganismos da cana-de-açúcar in natura hidrolisada com cal virgem. Revista Brasileira de Zootecnia, 40(4), 715-719. http://dx.doi. org/10.1590/S1516-35982011000400003.
44. Ordóñez, J. A. (2005). Tecnologia de alimentos: componentes dos alimentos e processos. São Paulo: Artmed.

45. Ramírez Granillo, A., Canales, M. G., Espíndola, M. E., Martínez Rivera, M. A., de Lucio, V. M., \& Tovar, A. V. (2015). Antibiosis interaction of Staphylococccus aureus on Aspergillus fumigatus assessed in vitro by mixed biofilm formation. BMC Microbiology, 15, 33. PMid:25880740.

Received: Apr. 14, 2020 Revised: Sept. 07, 2020 Accepted: Oct. 12, 2020 